Article

\title{
Complete Recycling of Composite Material Comprising Polybutylene Terephthalate and Copper
}

\author{
Fabian Knappich ${ }^{1,2, *}$, Ferdinand Hartl ${ }^{1}$, Martin Schlummer ${ }^{1}$ and Andreas Mäurer ${ }^{1}$ \\ 1 Fraunhofer Institute for Process Engineering and Packaging IVV, Process Development for Polymer \\ Recycling, Giggenhauser Straße 35, 85354 Freising, Germany; ferdinand.hartl@web.de (F.H.); \\ martin.schlummer@ivv.fraunhofer.de (M.S.); andreas.maeurer@ivv.fraunhofer.de (A.M.) \\ 2 Technical University of Munich, TUM School of Life Sciences Weihenstephan, Alte Akademie 8, \\ 85354 Freising, Germany \\ * Correspondence: fabian.knappich@ivv.fraunhofer.de; Tel.: +49-8161-491-311
}

Academic Editor: Michele Rosano

Received: 3 April 2017; Accepted: 2 June 2017; Published: 8 June 2017

\begin{abstract}
Composite materials comprising plastic and metal parts generate a large amount of waste containing valuable components that are difficult to separate and recycle. We therefore developed an economical solvent-based process for the recovery of costly manufactured composite materials comprising several copper panels over-moulded with a polymeric matrix of polybutylene terephthalate (PBT). We applied the CreaSolv ${ }^{\circledR}$ Process, which uses proprietary formulations with a low risk to user and environment, in order to dissolve the polymer and retain the inert copper. After separating the metal from the solution, solvent recovery was achieved by means of vacuum distillation and melt degassing extrusion. The recovered solvent was collected and recycled while maintaining its original properties. We tested two candidate solvents with PBT, measuring their impact on the molecular weight $\left(M_{\mathrm{W}}\right)$ and polydispersity of the polymer at different residence times and dissolution temperatures. We found that increasing the temperature-time-load had a negative effect on the $M_{\mathrm{w}}$. Both solvents we tested were able to dissolve the polymeric matrix within $30 \mathrm{~min}$ and with moderate energy consumption. Furthermore, we found that the exclusion of oxygen during dissolution significantly increases the quality of the recovered polymer and metal. We transferred the process from the laboratory scale to the small-technical scale and produced material for large analytical and mechanical quality evaluation, revealing no decline in the polymer quality by blending with new plastic. The recovered copper met virgin material properties. Therefore, both components of the original composite material have been recovered in a form suitable for reuse.
\end{abstract}

Keywords: polymer; recovery; solvent-based; automotive; WEEE; PBT; CreaSolv ${ }^{\circledR}$ Process

PACS Classification: 61.25.hk; 83.80.Sg; 82.35.Lr; 81.05.Qk; 68.35.bd

\section{Introduction}

In certain areas of application, tailor-made plastics now have properties which render them superior to natural materials and irreplaceable for modern technical applications. Composite materials containing plastic and metal parts are often used as electrical conductors, for example, in the automotive industry [1]. These plastic-metal hybrid components require complex manufacturing processes to shape the metal parts and introduce the polymer by over-moulding the metal with plastic melt [2]. Such processes often generate large amounts of production waste due to the narrow tolerances during quality control, and the resulting waste streams usually have a high material value due to the presence of both expensive metals and high-performance plastics characterized by high 
temperature and chemical resistance. A non-destructive process for the recovery of both components would therefore be highly beneficial.

Established methods for the recycling of metal-plastic composites are usually based on waste comminution followed by separation into different fractions [3]. The utilization of waste from electrical and electronic equipment (WEEE) is an important area of research, motivated by the recovery value of precious metals from electronic components such as cables and printed circuit boards (PCBs) $[4,5]$. However, the recovery of the plastic matrix is also increasingly important [6]. In conventional composite decomposition processes for cable scrap, composite waste comprising copper and polyvinyl chloride (PVC) is crushed in a shredder and then ground using bar, ball, roller, or hammer mills. Density separation methods, windings, and magnetic or electrostatic separators can then be used to separate the ground material, with the aim of minimizing the cross-contamination of the end products and recovering each component as pure as possible [7-12]. The best results for the separation of a metal-plastic composite (a parallel wire cable) were achieved by reducing the particle size to $\sim 3 \mathrm{~mm}$ in a cage mill followed by air-jet screening, resulting in $<1 \%$ cross-contamination [7]. The separation of ground cable waste with a particle size $<8 \mathrm{~mm}$ was carried out with the aid of an electrostatic precipitator, and $99.95 \%$ of the plastic and $98.8 \%$ of the copper fraction was recovered after optimizing the apparatus geometry, field strength, and humidity [10].

Mechanical pulping has also been investigated for the recovery of PCBs. For example, grinding to a particle size of $0.5 \mathrm{~mm}$ in a ball mill followed by a complex separation system involving various dry and wet processes achieved the recovery of $95 \%$ of the metal with $66 \%$ purity [13]. Furthermore, ground PCB material was concentrated from a hammer mill to $80 \%$ metal content using a circulating air classifier [14]. Because the plastic matrix must be recovered in addition to the metal, many of the well-known thermal-chemical recycling processes are unsuitable. Chemical recycling has been investigated for the recycling of PCBs, for example, in the form of pyrolysis [12,15-17], de-polymerization in supercritical liquids [18], or by gasification [19].

In order to obtain pure metal and polymer fractions, solvent-based recovery processes could also be applied. Present techniques use solvents like toluene, n-hexane, methyl-ethyl-ketone, or xylene, for instance, which are highly flammable and dangerous to health [20-22]. The process is applied for many different polymers (polypropylene, polyamides, polyolefin) and reveals adequate dissolution kinetics and polymer qualities; however, the recycling of metal-plastic composites and larger scale trials are not reported.

The CreaSolv ${ }^{\circledR}$ Process (CreaSolv ${ }^{\circledR}$ is a registered trademark of CreaCycle $\mathrm{GmbH}$ ), developed and patented by the Fraunhofer Institute for Process Engineering and Packaging IVV, uses special formulations with a low risk for both users and the environment, ideally not to be classified according to Globally Harmonised System (GHS) criteria. These selective solvents-mixtures extract the target polymers from heterogeneous waste input streams, allowing the polymer solution to be separated from undissolved components or harmful and / or prohibited pollutants, such as plasticizers or halogenic flame retardants. At the end of the process, the solvent is recovered by drying in order to ensure closed-loop circulation and to keep the process economically viable. The recycled polymer (product) is solvent free, meets the properties of virgin material, and is suitable as a substitute material in production processes [23-25].

Here, we modified the CreaSolv ${ }^{\circledR}$ Process to achieve the recycling of composite material comprising several copper panels over-moulded with a polymeric matrix of polybutylene terephthalate (PBT). Because the investigated waste streams are pure polymers (with the exception of the metal feeders), the cleaning and precipitation steps do not need to be integrated into this process. The metal parts are separated directly during the dissolution step by detaching the polymer matrix from the mechanically fixed conductor elements. The solvent recovered during the drying step can thus be recycled directly into the process. In particular, we investigated the influence of temperature on the kinetics of the dissolution and drying steps, as well as the influence of dissolution on the quality of the recovered recyclates. Due to the complexity of solvent-based recycling plants, the investment 
costs for the required equipment are fairly high in comparison to those for conventional mechanical recycling. For that reason, we identified the so-called debinding systems as state-of-the-art large-scale technologies for implementing our solvent-based PBT-copper recycling in a profitable way.

\section{Materials and Methods}

\subsection{Samples}

The composite material samples (Figure 1) were hybrid components $(190 \times 75 \times 30 \mathrm{~mm}, 74.5 \mathrm{~g})$ comprising PBT GF30, a polyester matrix (polybutylene terephthalate) with $30 \%(w / w)$ glass fibre reinforcement. The trade name is BASF Ultradur ${ }^{\circledR}$ B 4300 G6 (kindly provided by psm protech GmbH \& Co. KG, Marktschellenberg). Flat copper elements (comprising $0.1 \%(w / w)$ of tin) had been partly fixed to the surface by contact points either made of plastic or over-moulded with the PBT polymer, and represented $48.3 \%(w / w)$ of the total weight.

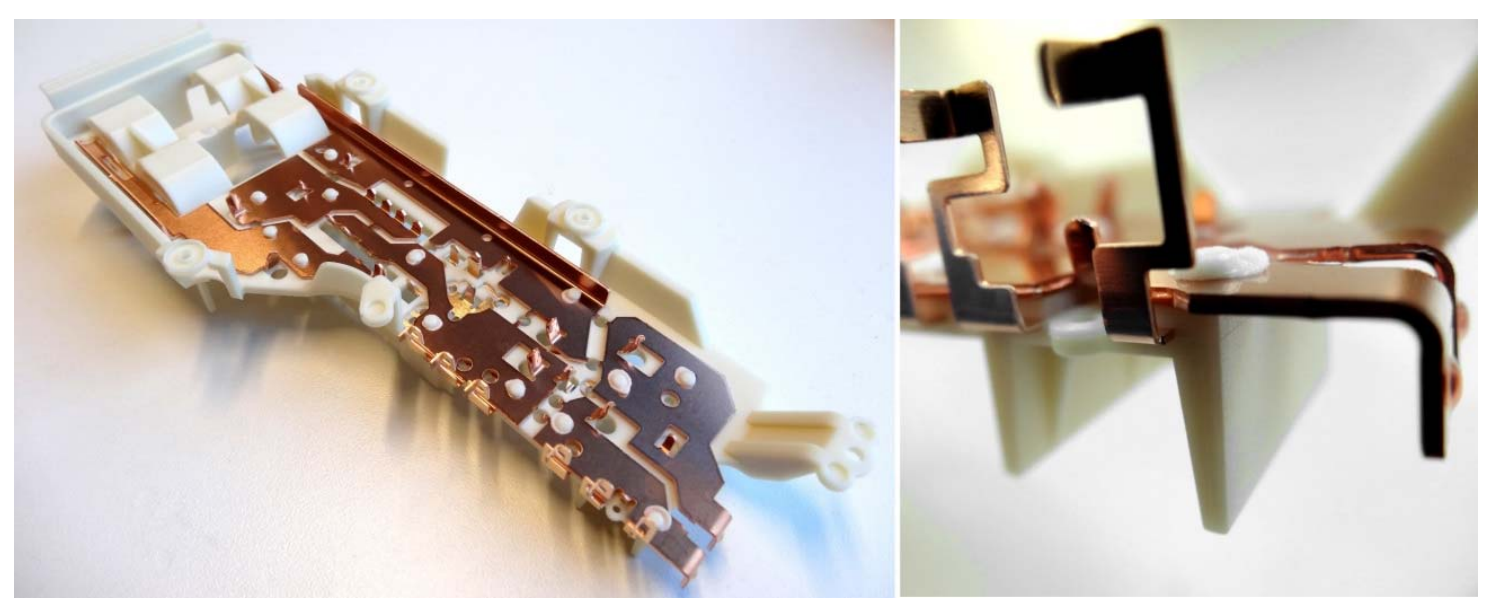

Figure 1. Investigated sample material comprising polybutylene terephthalate and copper.

The samples had been rejected from the production plant during manufacturing, but with few exceptions the reasons for rejection could not be determined by eye. This presumably reflected deviations from the working temperature of the injection mould, resulting in the incomplete filling of the cavity. More parts with bent copper contacts were also observed.

\subsection{Solvents}

As stated above, all six of the solvent mixtures tested were developed by $\mathrm{CreaCycle} \mathrm{GmbH}$, Grevenbroich. The selection of these so-called CreaSolv ${ }^{\circledR}$ Formulations was based on the solubility parameters according to Hansen [26]. Other factors included the commercial availability of the ingredients, the risk to user and environment, and the biological degradability [27]. The exact chemical compositions of the formulations are proprietary and so they are named herein using the terms “CreaSolv ${ }^{\circledR} 1$ ", “CreaSolv ${ }^{\circledR} 2$ ", . . , “CreaSolv ${ }^{\circledR} 6$ ". The mixtures 1-6 were composed of different types of solvents in order to examine their individual functionality and effectiveness. Table 1 shows the properties of the applied CreaSolv ${ }^{\circledR}$ Formulations. 
Table 1. Overview of the applied CreaSolv ${ }^{\circledR}$ Formulations.

\begin{tabular}{cc}
\hline Solvent & Properties \\
\hline CreaSolv $^{\circledR} 1$ & polar protic \\
CreaSolv $^{\circledR} 2$ & polar aprotic \\
CreaSolv $^{\circledR} 3$ & polar aprotic \\
CreaSolv $^{\circledR} 4$ & non-polar \\
CreaSolv $^{\circledR} 5$ & non-polar aprotic \\
CreaSolv $^{\circledR} 6$ & polar protic \\
\hline
\end{tabular}

Sample preparation for analytical issues was done using tetrahydrofuran and acetone, purchased from Merck KgaA, Darmstadt.

\subsection{Laboratory-Scale Methods}

The solvents were tested by placing $\sim 1-\mathrm{cm}$ polymer fragments in a 100-mL beaker and stirring with each solvent on a heating plate until the solvent became cloudy and the polymer showed signs of swelling. The solvents were tested at a minimum solution temperature $\left(T_{\mathrm{d}, \min }\right)$, causing a complete dissolution within a maximum time of $60 \mathrm{~min}$, and at 5-K increments to determine the exact temperature-dependent dissolution time $\left(t_{\mathrm{d}}\right)$. Based on our experiences regarding polymer concentration and its influence on dissolution time, viscosity, and solvent recovery, the mass balance was calculated to determine a final dry matter of the solution at $7.5 \%(w / w)$. Solvent loss during this process was ignored.

Dissolution was also monitored after excluding the oxygen using a stirred three-neck round-bottom flask combined with a mushroom heater. Nitrogen was introduced into the flask via one opening and a return condenser at another opening was used to prevent liquid evaporation by stripping the solvent. The exhaust gas stream was passed via a dip tube into a water trap. A gastight thermocouple at the third opening was used to measure the product temperature.

The parameters of the thermal drying process were investigated using an oil-heated vacuum rotary evaporator. The dry matter value of the polymer solution was determined by continuous gravimetric measurements of the evaporator flask. Wherever necessary (e.g., sample preparation for analysis), small amounts of the polymer solution were dried by repeated solvent extraction using acetone.

\subsection{Technical-Scale Methods}

Figure 2 shows the technical-scale process as a flow diagram. We used the debinding unit EDA-50 and the distillation unit LRA-50 (50-litre-scale in both cases) provided by Lömi GmbH, Großostheim. The entire test rig was operated in batch mode (i.e., the dissolution and drying processes were independent, time-separated partial steps). The debinding system (Figure 2 left) was a horizontally oriented oil-heated stainless steel container that could be opened and closed at the front using a hatch provided with a screw cap. Within the vessel, the PBT-copper parts were applied to a removable, roll-mounted frame $(500 \times 220 \mathrm{~mm})$ of perforated metal plates with spacers $(40 \mathrm{~mm})$. Therefore, the sample material did not have to undergo any previous cutting or sorting; we maintained its original dimensions, as described in Section 2.1. The heated solvent was introduced and circulated using a centrifugal pump at $20 \mathrm{~L} / \mathrm{min}$ and the remaining gas space was purged with nitrogen. After complete dissolution, the PBT-solution was conveyed to the distillation unit (Figure 2 right) containing a water-cooled solvent trap and an integrated water ring pump for vacuum generation. Because of the pressure decay, the polymer solution was sucked into the distillation unit, resulting in the partial flash evaporation of the solvent. The remaining solvent then was evaporated during the residence time of the non-stirred polymer solution. The copper parts and vessel surface within the debinding unit were then washed with uncharged solvent. The resulting dilute polymer solution with a dry matter value of $<1 \%(w / w)$ was available for the next dissolution batch. The residual solvent within the pre-dried PBT 
samples then was removed using a state-of-the-art melt degassing extruder at a throughput capacity of $1.5 \mathrm{~kg} / \mathrm{h}$.

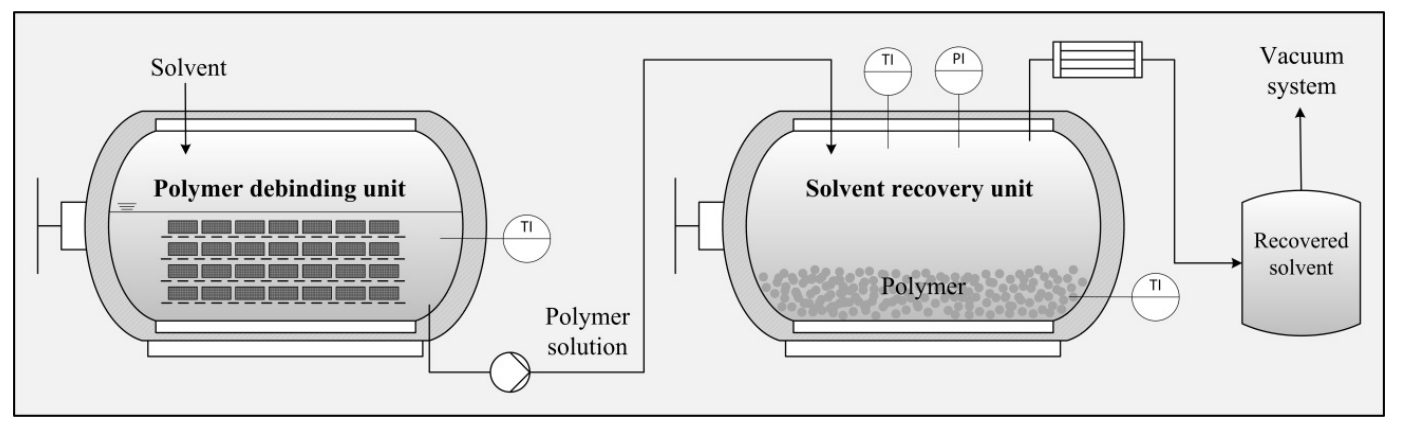

Figure 2. Process flow diagram of the technical-scale application.

\subsection{Analytical Methods}

The influence of the dissolution and drying processes on the molecular weight and polydispersity (PD) of the polymer were analysed by gel permeation chromatography (GPC) to measure qualitative changes in the PBT [28-30].

A gravimetric infrared moisture analyser served to determine the residual solvent content or the dry matter value (DM), respectively, of polymer-solvent mixtures. For smaller residual solvent amounts of the polymer, gas chromatography (HS-GC) based on multiple head-space injection was applied [31].

In order to estimate the glass fibre content of the PBT qualitatively, we used X-ray fluorescence analysis.

Melt flow rate (MFR) values of the solvent-free PBT samples were measured using a laboratory melt flow tester according to ISO $1133-1$ [32] at $250{ }^{\circ} \mathrm{C}$ and $2.16 \mathrm{~kg}$.

Differential scanning calorimetry (DSC) according to ISO 11357-1 was used to measure the melting temperature of the polymer samples [33,34].

Typical mechanical tests of the polymer, including vicat softening temperature (ISO 306), tensile modulus, breaking stress, elongation at break (ISO 527-1/-2), charpy impact strength (ISO 179-1eU at $23^{\circ} \mathrm{C}$ ), and charpy notched impact strength (ISO 179-1eA at $23^{\circ} \mathrm{C}$ ), were carried out together with Sysplast GmbH \& Co. KG, Nürnberg and Sitraplas GmbH, Bünde [35-37].

In order to evaluate the quality of the recovered copper elements, we applied a metallographic analysis. Therefore, a micro-section of the metal was measured using an incident light microscope.

\section{Results and Discussion}

\subsection{Dissolution Kinetics and Molecular Weight}

In order to investigate the influence of temperature on the dissolution time, single fragments of the PBT samples were mixed with each of the six CreaSolv ${ }^{\circledR}$ Formulations, but they only dissolved in CreaSolv ${ }^{\circledR} 1$ and 2. In both cases, the dissolution time was measured at four temperatures, as described above. Figure 3 shows the dissolution times at a final polymer concentration of $7.5 \%(w / w)$ as a function of temperature. As expected, the dissolution time $t_{\mathrm{d}}$ declined at higher temperatures because of an increased rate of diffusion/permeation and larger solubility parameter spheres [26]. The greatest reduction occurred within a $5 \mathrm{~K}$ interval above the minimum dissolution temperature $T_{\mathrm{d} \text {,min }}$. In both solvents, $t_{\mathrm{d}}$ decreased by $\sim 40 \%$ and fell slightly below the reported dissolution times of conventional solvents [20]. However, further increasing the temperature had little additional impact. The flattening curve at more than $10 \mathrm{~K}$ above $T_{\mathrm{d} \text {,min }}$ indicates no significant changes in the $t_{\mathrm{d}}$. We therefore selected a temperature that is $5 \mathrm{~K}$ above $T_{\mathrm{d} \text {,min }}$ as the optimum range for potential technical implementation. 


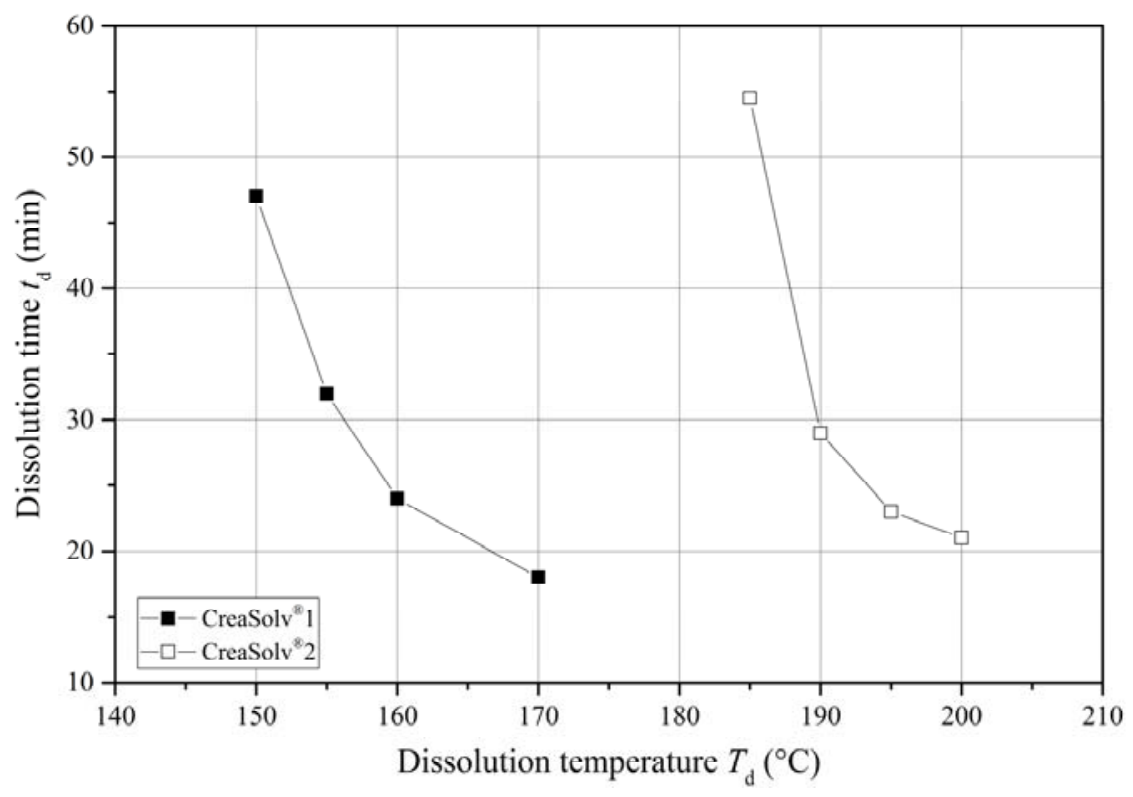

Figure 3. Diagram showing the dissolution time $t_{\mathrm{d}}$ depending on the dissolution temperature $T_{\mathrm{d}}$ using the two candidate solvent formulations $\mathrm{CreaSolv}^{\circledR} 1$ and 2 , respectively.

Furthermore, the $M_{\mathrm{W}}$ of PBT $\left(M_{\mathrm{w}, \mathrm{PBT}}\right)$ was measured by gel permeation chromatography, as a function of the dissolution temperature for the two solvents, and compared to the input material. CreaSolv ${ }^{\circledR} 1$ substantially reduced the polymer chain length, whereas CreaSolv ${ }^{\circledR} 2$ had only a limited effect, even at a higher temperature. Using a dissolution temperature of $190^{\circ} \mathrm{C}$, in the latter system, the $M_{\mathrm{W}, \mathrm{PBT}}$ declined by only $11 \%$ from $4.7 \times 10^{4} \mathrm{Da}(\mathrm{PD}=2.27)$ to $4.2 \times 10^{4} \mathrm{Da}(\mathrm{PD}=2.10)$. Oxygen may be responsible for the decreasing $M_{\mathrm{W}, \mathrm{PBT}}$ because solvent oxidation products can cleave the polymer by solvolysis. The dissolution process was therefore investigated in the absence of oxygen. For both solvents, the reduction in $M_{\mathrm{w}}$ was less severe under a nitrogen atmosphere. In the case of CreaSolv ${ }^{\circledR} 2$, the $M_{\mathrm{w}, \mathrm{PBT}}$ decreased by only $4 \%$ to $4.5 \times 10^{4} \mathrm{Da}(\mathrm{PD}=2.13)$. In the case of CreaSolv ${ }^{\circledR} 1$, at $155^{\circ} \mathrm{C}$, the $M_{\mathrm{w}, \mathrm{PBT}}$ decreased to $1.5 \times 10^{4} \mathrm{Da}(\mathrm{PD}=2.33)$, which is still far below the initial chain length. CreaSolv ${ }^{\circledR} 1$ is therefore not recommended as a solvent for PBT under the selected parameters because the material qualities of the recycled polymer would be completely lost by a reduction in $M_{\mathrm{W}, \mathrm{PBT}}$ of this magnitude. In contrast, CreaSolv ${ }^{\circledR} 2$ caused only a moderate decrease in the $M_{\mathrm{W}, \mathrm{PBT}}$, and the quality of the recycled polymer was therefore retained when CreaSolv ${ }^{\circledR} 2$ was used, despite the higher dissolution temperature.

In a further experimental series, the impact of the residence time $t_{\mathrm{r}}$ of CreaSolv ${ }^{\circledR} 2$ on PBT was investigated more closely. The dissolution again took place in a nitrogen atmosphere. Figure 4 shows the $M_{\mathrm{W}, \mathrm{PBT}}$ as a function of the temperature-time-load. For comparison, the values for dissolution at 190 and $200{ }^{\circ} \mathrm{C}$ but in oxygen atmosphere are also presented. We found that the rate of polymer degradation was initially slow, but increased with longer residence times. After the first $30 \mathrm{~min}$, the $M_{\mathrm{w}, \mathrm{PBT}}$ had fallen by only $10 \%$, but after a further $20 \mathrm{~min}$ it had fallen by $50 \%$. Nevertheless, CreaSolv ${ }^{\circledR} 2$ appears to be suitable for the successful recovery of PBT if oxygen is excluded, the temperature is maintained at $190^{\circ} \mathrm{C}$, and the residence time does not exceed $30 \mathrm{~min}$. 


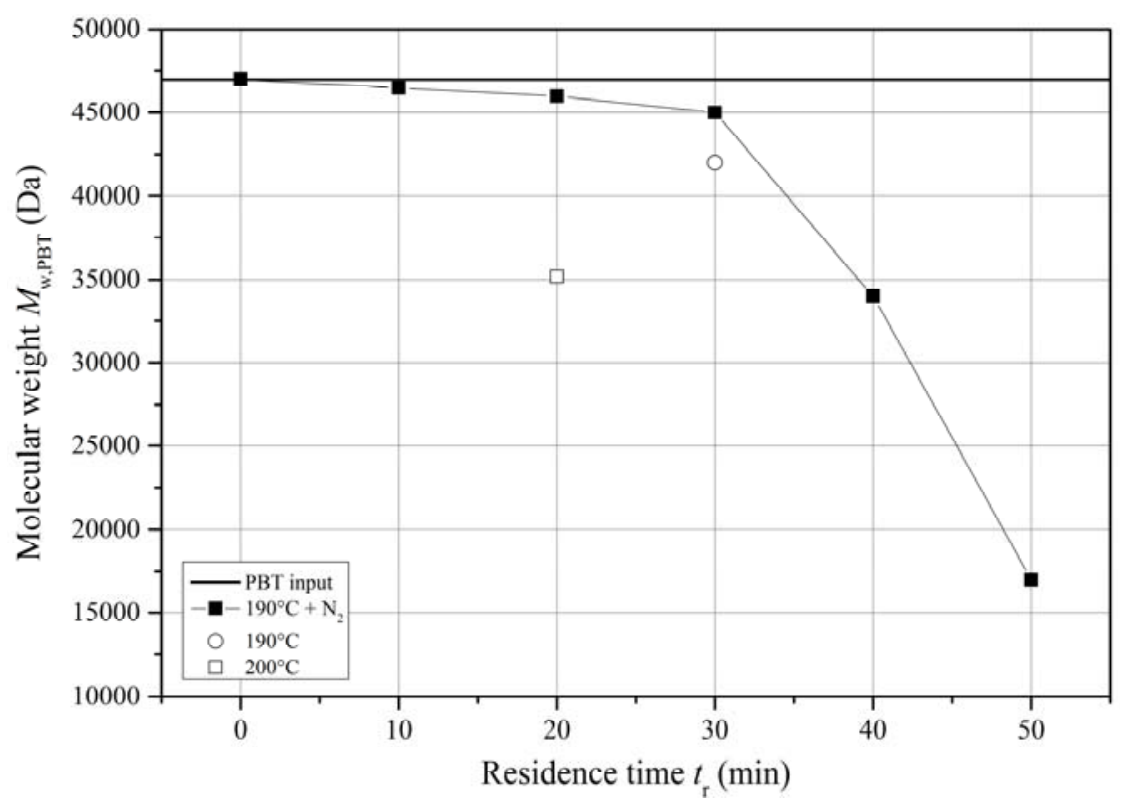

Figure 4. Diagram showing the molecular weight $M_{\mathrm{w}, \mathrm{PBT}}$ of the polymer depending on the residence time $t_{\mathrm{r}}$ during dissolution process using CreaSolv ${ }^{\circledR} 2$ with and without the exclusion of oxygen. PBT, polybutylene terephthalate.

\subsection{Drying Kinetics}

Having shown that the quality of the PBT polymer suffers at elevated temperatures, the drying of the polymer solution (dissolved in a nitrogen atmosphere using CreaSolv ${ }^{\circledR}$ ) was tested at $150{ }^{\circ} \mathrm{C}$ and 40 mbar using a rotary evaporator. This vacuum level approximately matches the typical lowest pressure levels that can be achieved using large-scale equipment. Figure 5 shows the dry matter value (DM) as a function of the $t_{\mathrm{r}}$.

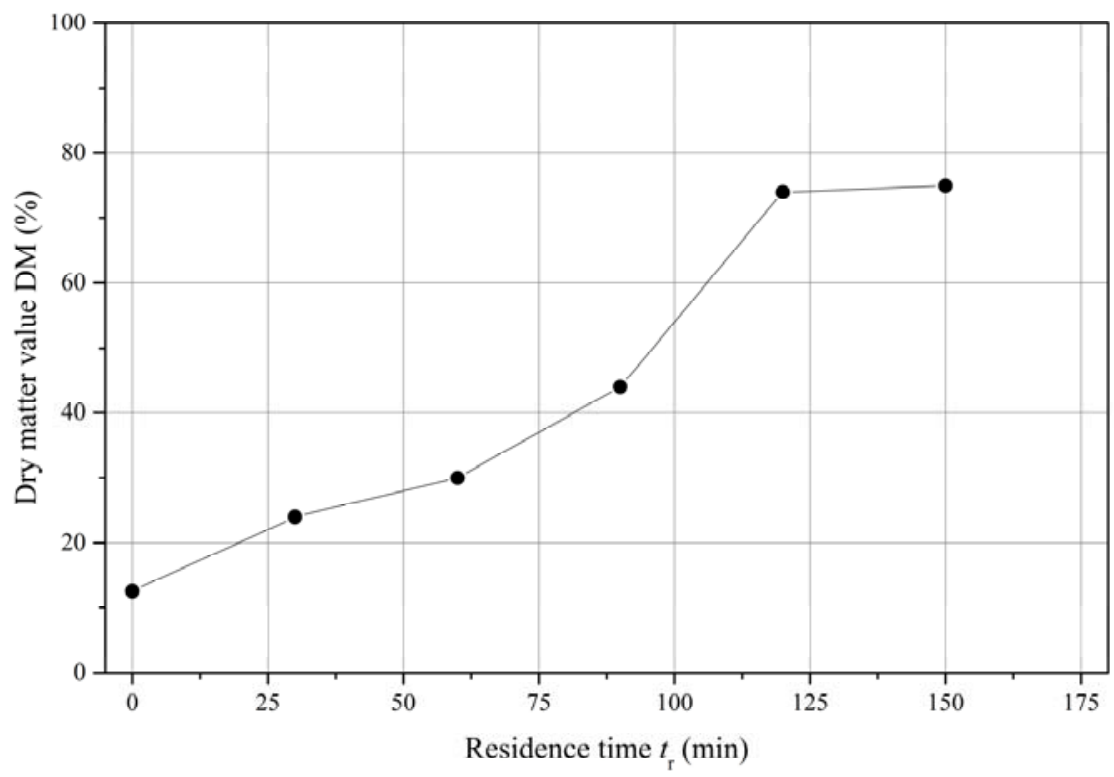

Figure 5. Diagram showing the dry matter value of the PBT-CreaSolv ${ }^{\circledR} 2$-sample depending on the residence time $t_{\mathrm{r}}$ during the drying process.

The measurements were stopped when there was no further indication of condensate flow. The curve of the drying velocity shows a near constant slope until a critical DM value of $\sim 75 \%(w / w)$ is 
achieved. Therefore, the process becomes inefficient at a residual solvent content of $\sim 25 \%(w / w)$, and the drying method was changed to that described for solvent extraction using acetone. As already stated, due to the small amount of sample material at this scale, the final drying using a melt degassing extruder was not applicable.

\subsection{Scale Up}

We found that it was feasible to transfer the process from the laboratory scale to the small technical scale using state-of-the-art equipment from the German project partner Lömi GmbH, Großostheim. The parameters were chosen based on the results described above (i.e., CreaSolv ${ }^{\circledR} 2$, a dissolution temperature of $190^{\circ} \mathrm{C}$, a residence time of $30 \mathrm{~min}$, and the exclusion of oxygen). Due to the absence of stirring (limited heat transfer) in both vessels, the dissolution time had to be adjusted to $60 \mathrm{~min}$ and the drying process was carried out using the same vacuum level but a higher temperature $\left(170{ }^{\circ} \mathrm{C}\right)$ than the laboratory-scale process until reaching a DM of $75 \%(w / w)$. As described above, the pre-dried polymer powder then was fed into a melt degassing extruder, dried completely, and compounded into granules with an output mass flow of $1.5 \mathrm{~kg} / \mathrm{h}$. The recovered solvent was collected and recycled while maintaining its original properties.

\subsection{Metal Quality}

The copper parts remain inert in the polymer solution; first their surface properties were evaluated. The samples obtained after dissolution in CreaSolv ${ }^{\circledR} 1$ and 2 both showed minor changes compared to the input material, in that the metal had a shiny surface. After recovery from the process, the surface of the metal material was dull. As indicated above, CreaSolv ${ }^{\circledR} 1$ appears to create a highly reactive milieu which not only degraded the polymer but also attacked the metallic surface. However, the copper parts recovered from the process using CreaSolv ${ }^{\circledR} 2$ in a nitrogen atmosphere showed no significant changes-visually or analytically (Figure 6). The metallographic analysis of the metals by comparing their micro-sections with those of virgin material showed no changes in structure. CreaSolv ${ }^{\circledR} 2$ therefore achieves a favourable outcome in regard to the recovery of the copper as well as the polymer.

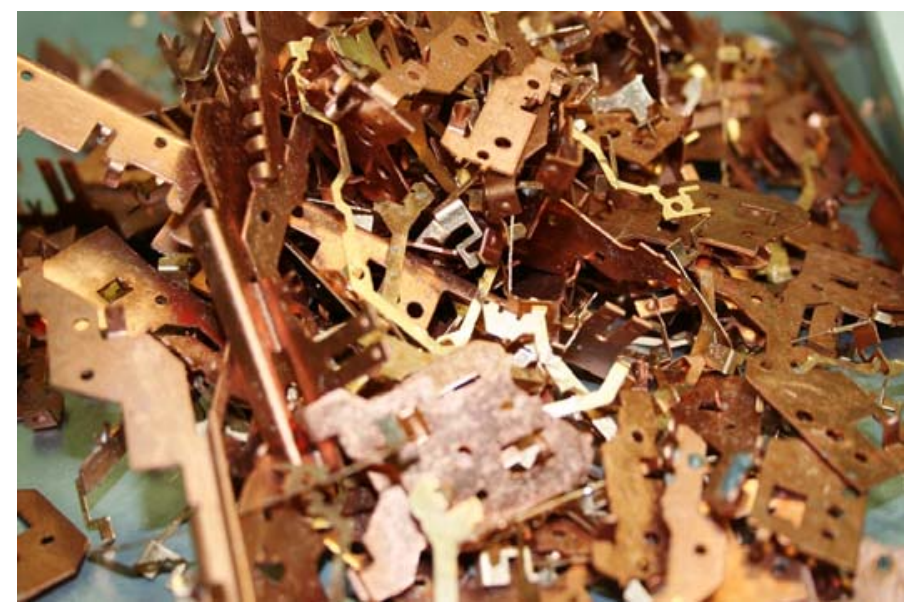

Figure 6. Recovered copper parts from CreaSolv ${ }^{\circledR}$ Process.

\subsection{Polymer Quality}

The quality of the polymer was evaluated by comparing the post-process recycled material from the small-technical-scale trials with the input PBT for the injection moulding. In order to evaluate a suitable application of the recycled PBT, we extruded a polymer blend with $90 \%(w / w)$ virgin material and also compared its properties to those of the pure cases (Figure 7). It was renounced to consider 
intermediates and/or products of the lab-scale trials, as they are unlikely to give a suitable indication for an industrial implementation of the process.

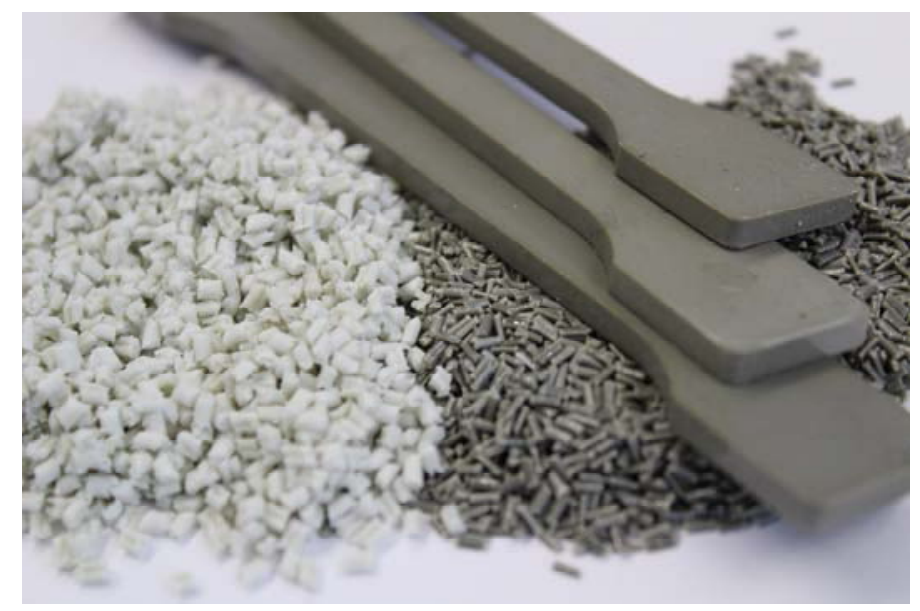

Figure 7. Recovered PBT material from CreaSolv ${ }^{\circledR}$ Process after solvent recovery: PBT-blend (left) and pure recyclate (right).

As shown in Table 2, the recycled PBT deviated substantially from the virgin material in terms of MFR and mechanical properties. The GPC results suggest this is caused by a reduction in polymer chain length [38]. We measured a drop of $M_{\mathrm{w}}$ from $4.6 \times 10^{4}$ Da to $2.1 \times 10^{4}$ (PDI $\left.=2.00\right)$ during dissolution and solvent recovery process, but no impact on the $M_{\mathrm{W}}$ coming from residual degassing within the extruder. The reduction seems to be due to the higher residence time in the debinding unit and the increased temperature in the solvent recovery unit. In addition, it is likely that a small number of enclosures containing residual solvent remain within the granules and cannot be removed completely, thus reducing the melt viscosity. The head-space gas chromatography revealed a residual content of $996 \mathrm{ppm}$, which is below the critical solvent threshold but might be still high enough to have an impact. As another reason for the decrease in viscosity, the content of the inert glass fibres and their orientation might be responsible [39]. Therefore, the virgin and recyclate samples were measured with X-ray fluorescence analysis. The silicon as well as the calcium content decreased by $55 \%$ and $38 \%$, respectively, which indicates a strong depletion of the glass fibres within the PBT matrix. This corresponds to the observation of sedimented fibres that remained at the bottom of the debinding unit after polymer extraction. The blend sample showed just the slightest decline in quality, which indicates a high possibility for a suitable reuse-at least as substitution for start-up or purge material. In any case, a detailed inspection of the extruded strands of the samples revealed no visible differences between the original PBT and the blend material in terms of surface texture or colour.

Table 2. Mechanical tests results of the recovered PBT from technical-scale trials in comparison to input polymer and a mixture thereof.

\begin{tabular}{cccc}
\hline Parameter & PBT Input Material & PBT Recyclate & PBT Blend \\
\hline Melting point $\left({ }^{\circ} \mathrm{C}\right)$ & 223 & 216 & 223 \\
Vicat softening temperature $\left({ }^{\circ} \mathrm{C}\right)$ & 213 & 177 & 209 \\
Tensile modulus $(\mathrm{MPa})$ & 8631 & 5710 & 8692 \\
Breaking stress $(\mathrm{MPa})$ & 120 & 30 & 120 \\
Elongation at break $(\%)$ & 7 & 1 & 7 \\
Charpy impact strength $\left(\mathrm{kJ} / \mathrm{m}^{2}\right)$ & 62 & 9 & 63 \\
Charpy notched impact strength $\left(\mathrm{kJ} / \mathrm{m}^{2}\right)$ & 7 & 3 & 7 \\
Melt flow rate $(\mathrm{g} / 10 \mathrm{~min})$ & 18 & 990 & 44 \\
\hline
\end{tabular}




\section{Conclusions and Economic Evaluation}

We have demonstrated that the CreaSolv ${ }^{\circledR}$ Process is suitable for the recovery of both copper and PBT components from a polymer-metal composite material. Nevertheless, the implementation of an industrial-scale process remains an economic challenge because large quantities of waste would be required. Under certain conditions, this technology instead offers a good opportunity for the economical recycling of composites already at smaller scales because both the metal and (high-priced) polymer components can be recovered, thereby achieving higher redemption prices. The annual turnover of such a process therefore does not need to match breakeven volume associated with mass-produced materials such as PVC. Even if the recovered polymer is lower in quality than the input material, it can nevertheless be mixed with virgin material and/or (glass fibre) master batches in order to reinforce the PBT matrix. Based on our experiences, for such a pilot plant we would estimate investment costs of $€ 750,000$. This would include a debinding unit with a capacity of $1 \mathrm{t} / \mathrm{d}$. In a worst-case scenario, we would reduce the redemption price of the recycled PBT from 1.70 (virgin PBT) to $1.10 € / \mathrm{kg}$ and the recovered metallic components from $5.45 € / \mathrm{kg}$ (virgin copper) to $4.30 € / \mathrm{kg}$. The processing energy for the (mechanical) pre-treatment of the copper parts which would be saved is not even included in the calculation. The material properties of the PBT blend (Table 2) indicate an in-house usage of the recyclate as substitute material for virgin polymer as the most useful application. The operating costs of such a plant are estimated with a lump sum of $750 € / \mathrm{d}$ for facilities, manpower, and maintenance in addition to the energy consumption by electrical power $(0.15 € / \mathrm{kWh})$, which depends on the throughput of each case. Based on these assumptions, the annual input would only need to increase to $100 \mathrm{t}$ to reach the breakeven point, even at moderate plant utilization (Table 3). In a very conservative scenario (case 4; no use of polymer, only metal recovery), the input quantity would have to increase to $170 \mathrm{t}$ to achieve a positive business case.

Table 3. Possible business cases for the implementation of the developed recycling process in production scale.

\begin{tabular}{ccccc}
\hline Description & Case $\mathbf{1}$ & Case $\mathbf{2}$ & Case 3 & Case 4 \\
\hline Input material & $102 \mathrm{t} / \mathrm{a}$ & $250 \mathrm{t} / \mathrm{a}$ & $365 \mathrm{t} / \mathrm{a}$ & $170 \mathrm{t} / \mathrm{a}$ \\
Operating time & $102 \mathrm{~d} / \mathrm{a}$ & $250 \mathrm{~d} / \mathrm{a}$ & $365 \mathrm{~d} / \mathrm{a}$ & $170 \mathrm{~d} / \mathrm{a}$ \\
Depreciation $(5$ years) & $-150,000 € / \mathrm{a}$ & $-150,000 € / \mathrm{a}$ & $-150,000 € / \mathrm{a}$ & $-150,000 € / \mathrm{a}$ \\
Operating costs & $-120,000 € / \mathrm{a}$ & $-307,000 € / \mathrm{a}$ & $-449,000 € / \mathrm{a}$ & $-200,000 € / \mathrm{a}$ \\
Metal value $(4.30 € / \mathrm{kg})$ & $+212,000 € / \mathrm{a}$ & $+519,000 € / \mathrm{a}$ & $+758,000 € / \mathrm{a}$ & $+353,000 € / \mathrm{a}$ \\
Polymer value $(1.10 € / \mathrm{kg})$ & $+58,000 € / \mathrm{a}$ & $+142,000 € / \mathrm{a}$ & $+212,000 € / \mathrm{a}$ & $+0 € / \mathrm{a}$ \\
Sum & $+/-0 € / \mathrm{a}$ & $+204,000 € / \mathrm{a}$ & $+371,000 € / \mathrm{a}$ & $+/-0 € / \mathrm{a}$ \\
\hline
\end{tabular}

The global consumption of PBT in the year 2012 was 830,000 $t, 32 \%$ of which was used for automotive applications including automotive electronics [40]. Assuming that at least this $32 \%$ is applied in polymer-metal hybrids comprising 50\% $(w / w)$ of PBT, 531,000 $\mathrm{t}$ of composites left the production line in 2012. Assuming a reject rate of 10\% of a company's total production volume, at least $53,000 \mathrm{t} / \mathrm{a}$ of industrial waste would be available. Based on the results of the presented work, there is plenty of opportunity with this output for an efficient, environmentally sustainable, and profitable recycling system based on the CreaSolv ${ }^{\circledR}$ Process, though the bundling of this highly dissipative waste generation might present a major challenge.

Acknowledgments: This work was supported by the Bavarian State Ministry of the Environment and Consumer Protection. The authors would like to thank the networking partners of the "ForCYCLE" project.

Author Contributions: Ferdinand Hartl realized the literature review and the laboratory-scale trials. Fabian Knappich carried out the technical-scale trials, was in charge of the mechanical testing, and wrote the paper. Martin Schlummer and Andreas Mäurer supervised the experimental work and reviewed the manuscript.

Conflicts of Interest: The authors declare no conflict of interest. 


\section{Abbreviations}

$\begin{array}{lll}M_{\mathrm{w}, \mathrm{PBT}} & (\mathrm{Da}) & \text { Molecular weight of PBT } \\ t_{\mathrm{d}} & (\mathrm{min}) & \text { Dissolution time } \\ t_{\mathrm{r}} & (\mathrm{min}) & \text { Residence time } \\ T_{\mathrm{d}} & \left({ }^{\circ} \mathrm{C}\right) & \text { Dissolution temperature } \\ T_{\mathrm{d}, \min } & \left({ }^{\circ} \mathrm{C}\right) & \text { Minimum dissolution temperature }\end{array}$

\section{References}

1. Hertel, G. Mercer-Studie Autoelektrik. Automob.-Elektron. 2007, 7, $26-27$.

2. Stransky, R. Current trends: Ever more electricity and plastic. Kunstst. Int. 2009, 6, 49-53.

3. Hagelüken, C.; Lee-Shin, J.U.; Carpentier, A.; Heron, C. The EU circular economy and its relevance to metal recycling. Recycling 2016, 1, 242-253. [CrossRef]

4. Zeng, X.; Yang, C.; Chiang, J.F.; Li, J. Innovating e-waste management: From macroscopic to microscopic scales. Sci. Total Environ. 2017, 575, 1-5. [CrossRef] [PubMed]

5. Izatt, R.M. Global Challenges, Consequences, and Prospects, 1st ed.; John Wiley \& Sons, Ltd.: West Sussex, UK, 2016.

6. Wang, R.; Xu, Z. Recycling of non-metallic fractions from waste electrical and electronic equipment (WEEE): A review. Waste Manag. 2014, 38, 1455-1469. [CrossRef] [PubMed]

7. Araujo, M.C.P.B.; Chaves, A.P.; Espinosa, D.C.R.; Tenorio, J.A.S. Electronic scraps-recovering of valuable materials from parallel wire cables. Waste Manag. 2008, 28, 2177-2182. [CrossRef] [PubMed]

8. Bevis, M.; Irving, N.; Allan, P. Recycling of metals and other materials: Recovery and re-use of polymeric cable scrap. Conserv. Recycl. 1983, 6, 3-10. [CrossRef]

9. Cui, J.; Forssberg, E. Mechanical recycling of waste electric and electronic equipment: A review. J. Hazard. Mater. 2003, 99, 243-263. [CrossRef]

10. Park, C.-H.; Subasinghe, N. Separation of covering plastics from particulate copper in caple wastes by induction electrostatic separation. Mater. Trans. 2015, 56, 1140-1143. [CrossRef]

11. Zhang, S.; Rem, P.C.; Forssberg, E. The investigation of separability of particles smaller than $5 \mathrm{~mm}$ by eddy current separation technology. Part I: Rotating type eddy current separators. Magn. Electr. Separ. 1999, 9, 233-251. [CrossRef]

12. Goodship, V.; Stevels, A. Waste Electrical and Electronic Equipment (WEEE) Handbook; Woodhead Publishing Ltd.: Cambridge, UK, 2012.

13. Das, A.; Vidyadhar, A.; Mehrotra, S.P. A novel flowsheet for the recovery of metal values from waste printed circuit boards. Resour. Conserv. Recycl. 2015, 53, 464-469. [CrossRef]

14. Eswaraiah, C.; Soni, R.K. Milling and classification of printed circuit board for materials recycling. Part. Sci. Technol. 2015, 33, 659-665. [CrossRef]

15. Hall, W.J.; Williams, P.T. Separation and recovery of materials from scrap printed circuit boards. Resour. Conserv. Recycl. 2007, 51, 691-709. [CrossRef]

16. De Marco, I.; Caballero, B.M.; Chomon, M.J.; Laresgoiti, M.F.; Torres, A.; Fernandez, G.; Arnaiz, S. Pyrolysis of electrical and electronic wastes. J. Anal. Appl. Pyrolysis 2008, 82, 179-183. [CrossRef]

17. Yang, X.; Sun, L.; Xiang, J.; Hu, S.; Su, S. Pyrolysis and dehalogenation of plastics from waste electrical and elctronic equipment (WEEE). A review. Waste Manag. 2013, 33, 462-473. [CrossRef] [PubMed]

18. Yildirir, E.; Onwudili, J.A.; Williams, P.T. Chemical recycling of printed circuit board waste by depolymerization in sub- and supercritical solvents. Waste Biomass Valoriz. 2015, 6, 959-965. [CrossRef]

19. Zablocka-Malicka, M.; Rutkowski, P. Recovery of copper from PVC multiwire cable waste by steam gasification. Waste Manag. 2015, 46, 488-496. [CrossRef] [PubMed]

20. Achilias, D.S.; Giannoulis, A.; Papageorgiou, G.Z. Recycling of polymers from plastic packaging materials using the dissolution-reprecipitation technique. Polym. Bull. 2009, 63, 449-465. [CrossRef]

21. Papaspyrides, C.D.; Kartalis, C.N. A model study for the recovery of polyamides using the dissolution/precipitation technique. Polym. Eng. Sci. 2000, 40, 979-984. [CrossRef]

22. Poulakis, J.G.; Varelidis, P.C.; Papaspyrides, C.D. Recycling of polypopylene-based composites. Adv. Polym. Tech. 1997, 16, 313-322. [CrossRef] 
23. Marwede, M.; Berger, W.; Reller, A.; Schlummer, M.; Mäurer, A. Recycling paths for thin-film chalcogenide photovoltaic waste-Current feasible processes. Renew. Energy 2013, 55, 220-229. [CrossRef]

24. Mäurer, A.; Schlummer, M. Good as new-recycling plastics from WEEE and packaging waste. Waste Manag. World 2004, 3, 33-43.

25. Menz, V.; Lefevre, J.; Schlummer, M. Werte wiedergewinnen. Kunststoffe 2012, 7, 72-75.

26. Hansen, C.M. Hansen Solubility Parameters-A User's Handbook, 2nd ed.; CRC Press: Boca Raton, FL, USA, 2007.

27. Creacycle GmbH. Company Homepage. Available online: www.creacycle.de (accessed on 15 October 2016).

28. Lathe, G.H.; Ruthven, C.R.J. The separation of substances on the basis of their molecular weights, using columns of starch and water. Biochem. J. 1955, 60, xxxiv. [PubMed]

29. Sandler, S.R.; Karo, W.; Bonesteel, J.; Pearce, E.M. Polymer Synthesis and Characterization: A Laboratory Manual; Academic Press: San Diego, CA, USA, 1998.

30. Skoog, D.A. Principles of Instrumental Analysis, 6th ed.; Thompson Brooks/Cole: Belmont, CA, USA, 2006.

31. Ettre, L.S. Headspace-Gas Chromatography. In Headspace Analysis of Foods and Flavors: Theory and Practice; Rouseff, R.L., Cadwallader, K.R., Eds.; Springer: Boston, MA, USA, 2001; pp. 9-32.

32. German Institute for Standardization. Plastics-Determination of the Melt Mass-Flow Rate (MFR) and Melt Volume-Flow Rate (MVR) of Thermoplastics (ISO 1133-1:2011); German version en ISO 1133-1:2011; German Institute for Standardization: Berlin, Germany, 2011.

33. German Institute for Standardization. Plastics—Differential Scanning Calorimetry (DSC) (ISO 11357-1:2009); German version en ISO 11357-1:2009; German Institute for Standardization: Berlin, Germany, 2009.

34. Höhne, G.; Hemminger, W.; Flammersheim, H.-J. Differential Scanning Calorimetry—An Introduction for Practioners; Springer: Berlin, Germany, 1996.

35. German Institute for Standardization. Plastics-Determination of Tensile Properties (ISO 527-1/-2:2012); German version en ISO 527-1/-2:2012; German Institute for Standardization: Berlin, Germany, 2012.

36. German Institute for Standardization. Plastics—Determination of Charpy Impact Properties (ISO 179-1:2010); German version en ISO 179-1:2010; German Institute for Standardization: Berlin, Germany, 2010.

37. German Institute for Standardization. Plastics-Determination of Vicat Softening Temperature (VST) (ISO 306:2013); German version en ISO 306:2013; German Institute for Standardization: Berlin, Germany, 2013.

38. Kelleher, P.G.; Wentz, R.P.; Hellman, M.Y.; Gilbert, E.H. The hydrolotic stability of glass fiber reinforced poly(butylene terephthalate), poly(ethylene terephthalate) and polycarbonate. Polym. Eng. Sci. 1983, 23, 537-542. [CrossRef]

39. Czarnecki, L.; White, J.L. Shear flow rheological properties, fiber damage, and mastication characteristics of aramid-, glass-, and cellulose-fiber-reinforced polystyrene melts. J. Appl. Polym. Sci. 1980, 25, 1217-1244. [CrossRef]

40. Bernnat, A.; Eilbeck, P.; Dirlenbach, J. Strong in electronics and automotive construction: Polybutylenterephtalat (PBT). Kunstst. Int. 2013, 10, 67-70. 